\title{
INTEROPERABILITY OF VARIOUS DATA STREAMS WITHIN GUYANA’s MRV SYSTEM
}

\author{
Pete Watt ${ }^{1}$, Pradeepa Bholanath ${ }^{2}$, Nasheta Dewnath ${ }^{2}$,Towana Smartt ${ }^{2}$, Chaplin Chan $^{1}$, Daniel Donoghue ${ }^{3}$ \\ ${ }^{1}$ Indufor Asia Pacific Ltd, Auckland City 1147, New Zealand - pete.watt@indufor-ap.com, chaplin.chan@indufor-ap.com \\ ${ }^{2}$ Guyana Forestry Commission, 1 Water Street, Georgetown, Guyana - project.coordinator@forestry.gov.gy, \\ ndewnath@gmail.com, towanasmartt@yahoo.com \\ ${ }^{3}$ Durham University, Stockton Road, Durham, DH1 3LE, UK- danny.donoghue@durham.ac.uk
}

KEY WORDS: Guyana, MRVS, Satellite Imagery, Forest Change Monitoring, REDD+, Data Interoperability, Data Agnostic Systems, Earth Observation

\begin{abstract}
:
In 2010 Guyana started work on the development of a national Monitoring Reporting and Verification System (MRVs) to quantify and measure the changes in the country's forest cover carbon and carbon emissions. A necessary part of this process involved the identification of reliable Earth Observation data of sufficient resolution to detect and quantify land use change in Guyana's forests. Over the past 10 years the MRVs has evaluated and integrated many data streams used to; map nationalscale forest change, support the analysis, and importantly datasets suitable to determine the accuracy of the change area mapped. Guyana's approach has evolved over time, to accommodate new technologies, but at its core the MRVs recognises the importance of local management, existing datasets and linking these elements to appropriate EO data such as Landsat, RapidEye, Sentinel, Planet Scope and very high spatial resolution aerial imagery. From the outset the MRVs development was divided into phases. This approach recognises that not all MRVs reporting functions can be satisfied immediately. For Phase 1 (Years 2010 to 2014) of the MRVS, historical change analysis was conducted using Landsat $30 \mathrm{~m}$ resolution imagery. Being a persistently cloudy country alternative EO data sources were included, with Landsat and DMC imagery largely superseded by $5 \mathrm{~m}$ resolution RapidEye imagery. After five years of monitoring the forest change baselines, methods, reporting processes and standard operating procedures had been well established and able to provide the required performance-based indicators. The focus of MRVs phase 2 (Years 2015 to 2019) was to retain the reporting standards already achieved while also streamlining processes, improving functionality and reducing operational costs (i.e. the reliance on commercial image data) post-2019. Process improvements and operational research targeted two areas; the feasibility of using freely available Landsat and 10 metre resolution Sentinel data to map countrywide deforestation, and development of a sample-based approach to estimate degradation from aerial imagery and Planet Scope (3-5 metres resolution). Guyana's move to integrate multiple data streams has been driven by the need for higher temporal resolution, repeated monitoring, and the creation of a data agnostic system to supports multiple decision-making processes on forest management. While the originally the MRVs was intended to support REDD+ reporting, the flexibility of the system design has meant it is proving to be invaluable tool for natural resources management in Guyana.
\end{abstract}




\section{INTRODUCTION}

Guyana is a tropical country located on the Caribbean coast of South America between $2^{\circ}$ to $8^{\circ} \mathrm{N}$ and $57^{\circ}$ to $61^{\circ} \mathrm{W}$. It shares common borders with Venezuela, Brazil and Suriname. The country has a land area of 21.1 million ha with a forest area of 18.5 million ha $(87 \%)$. The Government of Guyana aims to protect and maintain its forests by attracting investment to foster growth and development that follows a low carbon emissions pathway. The Conference of the Parties (e.g. COP16 and COP21) of the United Nations Framework Convention on Climate Change (UNFCCC) requests countries to report reference greenhouse gas emission levels and/or forest change reference levels using certified, consistent and verifiable methodologies and common metrics so these can be assessed by the Intergovernmental Panel on Climate Change (IPCC). This involves individual countries developing monitoring, reporting and verification (MRV) systems able to generate detailed annual reports on national land use change (activity data) and related $\mathrm{CO}_{2}$ emission factors (EF) in an IPCC format for audit by the UNFCCC Reduced Emission from Deforestation and Forest Degradation (UN-REDD) programme. The reporting requirements include initiatives on conservation, sustainable management of forests and enhancement of forest stocks (REDD+). The audit function presents considerable challenges for many developing countries that lack national forest inventories, access to frequently updated national land cover maps, technical expertise and resources.

Prior to 2009 Guyana reported approximate forest change values, collated and published via the FAO global Forest Resources Assessments (FRA). This value can be described as a best estimate of national forest change. In 2009 the Governments of Guyana and Norway agreed to cooperate on broader emission reduction goals under the umbrella of UNFCCC-REDD + . The objective to develop an MRV system (MRVs) allowing for a comprehensive, consistent, transparent and verifiable assessment of forest area change (GOFC-GOLD, 2016; GFOI, 2016). While committing up to US\$250 million over the period of the Agreement ( 5 years), the level of support was to be determined by Guyana's delivery of results against two sets of indicators:

- Indicators of enabling activities: a set of policies and safeguards designed to ensure REDD+ contributes to the achievement of the goals set out in the Agreement. These indicators spoke to arrangements to ensure systematic and transparent multi-stakeholder consultations throughout the process; protection of the rights of indigenous peoples; ensuring environmental integrity and biodiversity protection; ensuring continuous improvements in forest governance; and providing transparent, accountable oversight and governance of the financial support received.

- REDD-plus Performance Indicators: a set of forest-based greenhouse gas emissions-related indicators. It was agreed that these would gradually be substituted as the MRVs became fully operational. They were developed based on conservative estimates while encouraging the development of a more accurate MRVs over time through building national capacities. These REDD+ Performance Indicators sought to contribute to the development of the national MRVs, based on internationally accepted methodologies and following the IPCC reporting principles of completeness, consistency, transparency, uncertainty, comparability, and encouragement of independent international review of results.

The agreement divided Guyana's MRVs programme into two stages: phase 1 running from 2010 to 2014 was designed to establish several interim measures, while phase 2 running from 2015 to 2020 was planned to consolidate and expand capacities for national REDD + monitoring, thereby underpinning results-based REDD + compensation in the long-term. To date, the GFC has completed eight national assessments. The results of each have been independently verified by third party verifiers.

With one year remaining to the end of Norway's funding commitment this paper intends to showcase Guyana's MRVS and the associated satellite imagery and GIS datasets that were used for the national assessments. It also provides a summary of Guyana's progress towards implementation of REDD+ and how interoperability of various data streams has helped to build and extend Guyana's MRVS to become a versatile platform that supports natural resource decisionmaking.

\section{MRV SYSTEM DESIGN}

Guyana's MRVS design and development started during a period when no comparable national-scale systems existed. While definitions, guidance material and good practice guidelines had been drafted (GOFC-GOLD, 2008), a template for fulfilling the reporting requirements under REDD+ was not provided. As early adopters this presented the opportunity to mould the design to expand beyond the core REDD+ monitoring and reporting functions.

With a blank canvas Guyana set about identifying key system requirements to enable annual reporting of deforestation and degradation. The Guyana Forestry Commission (GFC) was the responsible agency tasked with the monitoring and reporting function. Indufor Asia Pacific (IAP) was engaged to support ongoing system development.

Development began in earnest in 2009. Challenges that needed to be addressed were identified at the early stages of the system design: Guyana's forest definition, annual reporting timelines, high levels of cloud cover, and lack of familiarity of the GFC GIS staff with remote sensing software. A need for the system to be data agnostic and capable of incorporating multiple space-borne datasets became evident from the outset. As pointed out by Lehmann et al. (2015), multi-sensor frameworks will continue to generate significant interest for international forest monitoring initiatives because of the increasing availability of spaceborne data. 


\subsection{Guyana's Forest Definition and Establishing Benchmarks}

The definition of what constitutes a 'forest' is the corner stone of any MRVs as it defines forest land and the monitoring extent. Guyana adopted the definition as outlined in the Marrakech Accords (UNFCCC, 2001); land is classified as forest if there is a minimum $30 \%$ tree canopy cover at a minimum tree height of $5 \mathrm{~m}$ covering a minimum area of 1 ha

In accordance with the agreement with the Norwegian government the national forest cover as at 1990 was used as a starting point. From this baseline forest change is documented to determine the rate of forest change. Under the agreement this information is used to inform the progress of several Interim measures relative to benchmark values set as at September 2009. Within this framework the steps and core inputs required to establish the MRVs are as follows:

- Determining the forest area as at 1990 using medium resolution satellite images (Landsat) by excluding non-forest areas (including existing infrastructure)

- Accounting for forest to non-forest land use changes between 1990 and 2009 using a temporal series of satellite data.

- Establishing a benchmark period (1990-2009) and a 30 September 2009 'benchmark map' as a reference point.

- Comparing annual change post-2009 against the 2009 benchmark.

In keeping with international best practice, the developed process uses a wall-to-wall approach that enables complete, consistent, and transparent monitoring of land use and land use changes over time. The approach allows for land cover change greater than one hectare in size to be tracked through time and attributed by its driver such as mining or shifting agriculture. This is in accordance with Approach 3 in the Good Practice Guidance for Land Use, Land-Use Change and Forestry IPCC report (Penman et al., 2003).

\subsection{Capacity Building}

The most important aspect of the Guyana/Norway agreement was the requirement to build national capacity to enable the reporting of annual national forest change. The design of the MRVs sought to capitalise on the professional skills and knowledge of the GFC's staff in the use of their GIS software which is used extensively in support of GFC's management functions. Over the years of development of Guyana's MRVs, significant capacity has been built within the local organisational structure of the Guyana Forestry Commission where the system is housed. The system started at a point with predominantly external consultants' support and has developed to a point where only new development features involve the inputs of consultants. GFC's proactive management and ownership of the MRVs reporting requirements have smoothed this transition, underpinned by the retention of core staff and the development of Standard Operating Procedures (SOP).

\subsection{System Design}

An overview of the processes, datasets and outputs of the MRVs is given in Figure 1. Access to the monitoring products of the MRVs by the National Agencies responsible for the management of the land resources is planned.

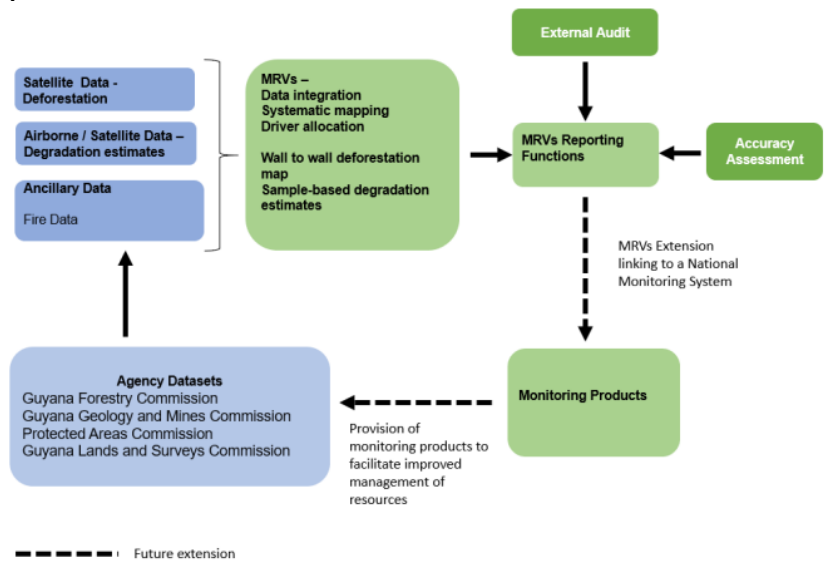

Figure 1. Overview of Guyana's MRVs

\subsection{Software}

The MRVs design focused on presenting the user with an intuitive visual GIS front-end using ArcGIS software thereby utilizing and building on the GFC staff familiarity with existing data input tools, data queries, spatial analyses, map manipulation and reporting. Customised extensions for systematic deforestation mapping and driver allocation were designed and implemented. Further improvements to the MRVs made post 2015 in line with the second phase of the MRV included implementation of a sample-based design to provide estimates of degradation.

Outside of the GIS framework, Guyana-specific image processing routines were developed using ENVI image processing software to normalise imagery, automate the extraction of deforestation boundaries, and identify areas of persistent cloud cover. At a later phase of the MRVs development the image processing routines were moved from commercial software to a cloud-based system supported by Google to take advantage of the online image datasets and the computation speed offered by the cloud. This strategy sits within the MRV Roadmap's mandate to continue to develop the MRVs along a low-cost pathway, where both image and software costs are minimised.

\subsection{Data Structure}

The spatial and attribute and related data are stored in a consolidated geodatabase backend for which data models and storage protocols were designed and implemented. The database holds all relevant spatial data, metadata about the dataset, its location on the network and anticipated update frequency.

Satellite image datasets downloaded from the image providers are stored as raster datasets and catalogued based on the analysis period. Metadata information includes the 
sensor, path and row (Tile ID), and the processing routines that have been applied to the images.

All results are subject to an external third-party annual audit which is intended to review the analysis processes and consistency and accuracy of the results. In line with the guiding principles for an MRV GFC's system strives to support the auditing function by documenting and archiving all information in the geodatabase.

\subsection{Management Level GIS Datasets}

Several Government agencies that are involved in the management and allocation of land resources in Guyana, hold spatial datasets. Since 2010 GFC has coordinated the storage of these datasets for the MRVS. These agencies fall under the responsibility of the Ministry of Natural Resources and the Ministry of the Presidency in Guyana and are responsible for forestry, mining, and land use planning and coordination. The main management data layers are summarised below, in Table 1 and are mainly used to provide context/background information that supports the annual mapping exercise.

\begin{tabular}{|c|c|c|}
\hline \multirow{3}{*}{$\begin{array}{l}\text { Ministry } \\
\text { Natural } \\
\text { Resources }\end{array}$} & Agency & Data Held \\
\hline & $\begin{array}{l}\text { Guyana Forestry } \\
\text { Commission (GFC) }\end{array}$ & $\begin{array}{l}\text { Resource } \\
\text { management } \\
\text { related datasets }\end{array}$ \\
\hline & $\begin{array}{lr}\begin{array}{l}\text { Guyana } \\
\text { and }\end{array} & \text { Geology } \\
\text { Commission } & \\
(\text { GGMC) } & \\
\end{array}$ & $\begin{array}{l}\text { Mining } \\
\text { concessions, } \\
\text { active mining } \\
\text { areas }\end{array}$ \\
\hline $\begin{array}{l}\text { Department } \\
\text { of } \\
\text { Environment }\end{array}$ & $\begin{array}{l}\text { Protected Areas } \\
\text { Commission }\end{array}$ & $\begin{array}{l}\text { Spatial } \\
\text { representations } \\
\text { of all protected } \\
\text { areas }\end{array}$ \\
\hline $\begin{array}{l}\text { Ministry of } \\
\text { the } \\
\text { Presidency }\end{array}$ & $\begin{array}{l}\text { Guyana Lands and } \\
\text { Surveys } \\
\text { Commission } \\
\text { (GL\&SC) }\end{array}$ & $\begin{array}{l}\text { Land tenure, } \\
\text { settlement } \\
\text { extents and } \\
\text { country } \\
\text { boundary }\end{array}$ \\
\hline
\end{tabular}

Table 1. Agency datasets provided

\section{INTEGRATION of MULTIPLE SATELLITE DATA STREAMS}

The datasets used for the change analysis have evolved over time-moving progressively from establishment of baselines required to monitor deforestation to the inclusion of datasets and development of methods required to estimate and report degradation.

Mapping of the 1990 forest extent was undertaken using Landsat imagery supported by 1991 JERS-1 radar data and historical 1960-era aerial photography. The latter datasets were used to verify the location of the forest/non-forest fringe and vegetation composition. Change analysis from 1990 to 2009 was conducted primarily with Landsat imagery, supported as required with IRS and CBERS images. As pointed out by Schingler (2015), the establishment of robust reference points would be challenging without science-grade legacy datasets such as Landsat.
After 2009 Guyana's MRVs moved to annual reporting of deforestation. Under the Norway / Guyana agreement the schedule of performance-based payments was referenced against the 2009 benchmark map that provided a snapshot of forest change as at 30 September 2009. The agreement imposed the constraint of including images acquired between August and December of each year. Given the persistent cloud cover and the temporal frequency of Landsat 5 (16 days) and image quality issues affecting Landsat 7, commercial DMC imagery was tasked. This ensured the acquisition of enough cloud-free images required to map and report deforestation by forest change driver.

From 2011 onwards these datasets were primarily superseded with high-resolution images from RapidEye. With a constellation of five satellites RapidEye allowed higher temporal and spatial resolution $(5 \mathrm{~m})$. The advantages were twofold, reducing risk of cloud obscuring change and improving the ability to assess degradation. Improvements post 2015 included a shift to the use of free Sentinel 2 imagery and testing and use of $3 \mathrm{~m}$ PlanetScope data.

\section{NATIONAL FOREST MONITORING - PROGRESSIVE IMPROVEMENTS}

The phased approach of the MRVs allowed for the progressive development of the system. Targeted improvements were included to keep pace with evolving reporting requirements and Guyana's continued desire to better understand the forest change drivers and their overall contribution to carbon emissions. Early on mining was identified as one of the main drivers of deforestation and degradation, contributing to around $90 \%$ of the forest loss in any one year.

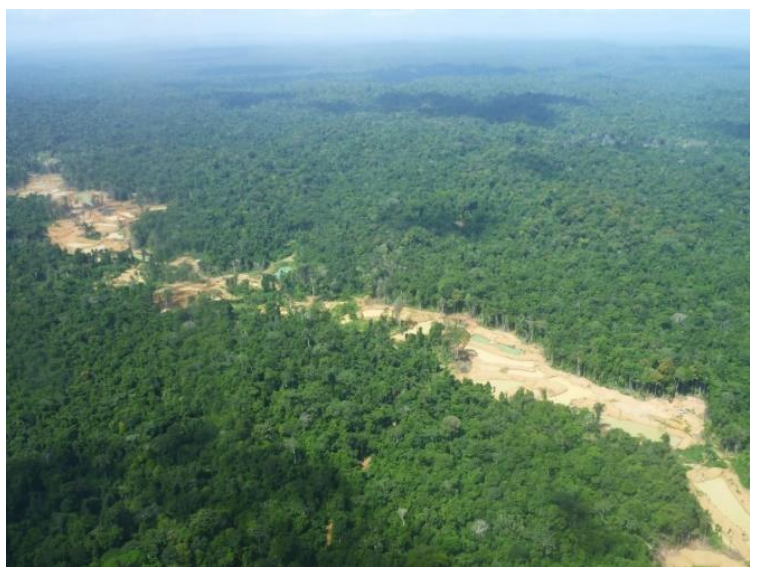

Figure 2. Example of a typical ribbon pattern of alluvial mining practice.

The legacy of Guyana's MRVs offers a unique insight with nearly 30 years of continuous national-scale monitoring. A defining feature is the accuracy of the monitoring dataset which has routinely met and exceeded annual audit requirements. It has consequently been used as a reference point in several recent scientific papers, e.g. Bovolo \& Donoghue (2017), Pickering et al., (2019), Galiatsatos et al., (submitted).

Data interoperability was an important consideration in the design and development of the MRVs given the multiple 
types of data being analysed, the need for data sharing, and updates to the system. This recognises that to improve accuracy, detect small scale changes, increase monitoring frequency and cost- effectiveness a process of continual review and adaptation is required.

Figure 3 identifies the timing of various improvements made to the MRVs, including the shift to annual reporting, national estimation of degradation, improvements in the accuracy assessment processes, and lastly deployment of a low-cost Guyana-managed MRVs.

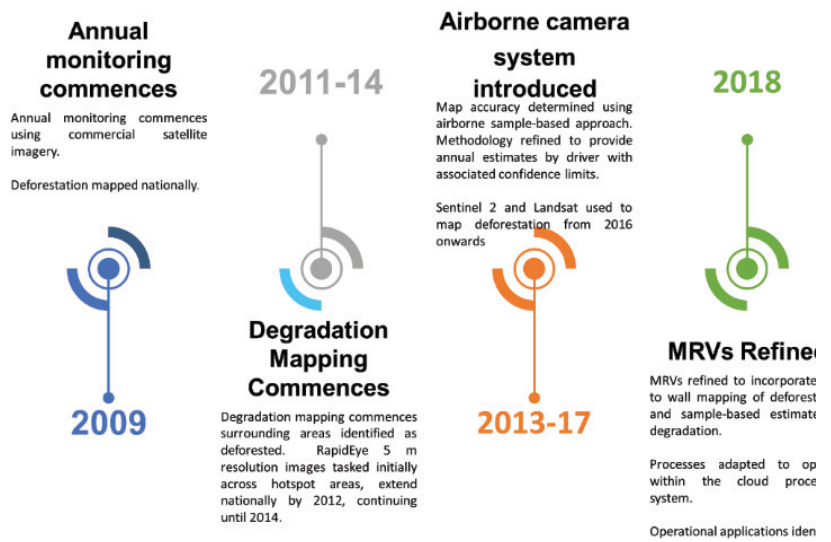

Figure 3. MRVs progressive improvement timeline

Some developments were intuitive, for example the move in 2009 to commercial imagery. This was prompted by the constraints placed on permissible image collection dates (August to December) and the risk of not attaining sufficient cloud-free imagery to report on the results-based indicators - a point amplified by the 2011 failure of Landsat 5 after 25+ years of imaging. Commercial DMC satellite imagery was introduced in 2010, and while suitable for deforestation events ( $>1$ ha) it was not a viable alternative to Landsat, nor a solution suitable for reporting on forest degradation impacts.

Reporting degradation impact is an area of continual review and study within the remote sensing community (e.g. Herold et al., 2011, FAO, 2011, Mitchell et al., 2017). Under the Norwegian agreement Guyana was required to identify and map degradation surrounding deforestation events. While a country-specific criterion was used the underlying IPCC definition of degradation still applied (IPCC, 2016). As a first step RapidEye imagery was tasked over $54 \%$ of Guyana to capture the main areas of change. The improved resolution enabled better identification of change boundaries, drivers of change and areas of forest degradation. RapidEye continued to be used between 2011 to 2014 with annual coverages routinely captured between August and December each year. This was complimented with some processing of spaceborne SAR (ALOS Palsar) data. The resulting map products included national maps of deforestation and degradation.

While these outputs met the reporting requirements several challenges were identified, namely having enough cloudfree coverage with adequate spatial and temporal resolution to accurately capture degradation extent. Outside the technical domain the financial cost of RapidEye and increasing requirement to provide degradation estimates for drivers such as shifting cultivation, infrastructure and forest harvest were also relevant.

Since inception the quality of annual forest change estimates had been independently evaluated using recognised statistical methods (Herold et al., 2006; Powell et al., 2004; Khorram, 1999). To mitigate the cloud risk, high-resolution imagery was captured using a Cessna-mounted aerial multispectral imaging system post 2013. The strategy employed uses the imaging system to capture high-quality image data at sites pre-determined by a two-stage stratifiedrandom sample design that provides good coverage of the strata with high and medium risk of change.

The camera system (Aeroptic/ aka GeoVantage) is transferable to various models of a light aircraft able to capture data between 25 to $60 \mathrm{~cm}$ (varied by the altitude of the aircraft at the time of capture) - a resolution capable of identifying forest degradation with some certainty. For reference Figure 4. shows small-scale clearance of forest between two years.

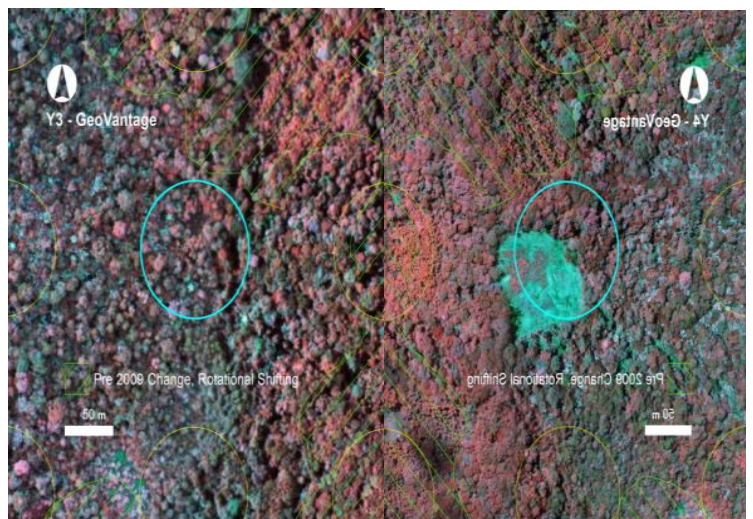

Figure 4. Aerial survey comparative time series data years 2012 (left) and 2013 (right)

Full sample coverage was achieved by including satellite imagery such as PlanetScope over stratum with a low risk of forest change and over areas where it is not possible to safely operate a small aircraft.

While the process was originally intended to provide area estimates of the deforestation and degradation as a comparison against the MRVs mapping it became evident that the sampling approach is very efficient, prompting the decision to shift from mapping degradation to obtaining a national estimate using the sampling approach.

The routine use of the MRVs data is now being integrated within Guyana's ministries, and specifically mandated uses are being explored for areas of resource management. The main constraint identified is data lag associated with annual reports, in that the reporting conducted by the GFC is retrospective, rather than providing frequently updated data in a near real time monitoring system. The GFC is currently advancing a process of developing a Continuous Resources Monitoring System building on the platform of the MRVS.

\section{DISCUSSION}

Guyana's experience has shown that there are shortcomings in the use of satellite imagery for national assessment of 
forest cover. Some of the factors that affect the practicality of using certain datasets include cost, revisit frequency, resolution, need for historic coverage, cloud cover and desire for continuous and real-time monitoring versus one-off monitoring. Guyana has attempted to strike a balance by evaluating various options, striving to achieve the most feasible and practical outcome.

From 1990 to 2009, there were limited land cover datasets at 20-30 m resolution. Landsat uniquely fulfils this role with the program referenced as a 'gold standard' by which other sensors have been compared due to its historical legacy, availability of data, global imaging, and superior calibration (Goward et al., 2017). Thus, it serves as the central reference point to which most moderate and high-resolution optical satellite systems are compared against even to the present day (Wulder et al., 2019). For Guyana Landsat was the only option that offered historic 1990 to 2009 coverage. However insufficient data prevented the production of annual forest change maps resulting in a decision to create forest change datasets covering three epochs: 1990-2000, 2000-2005, and 2006-2009.

Guyana's first year of annual assessment was 2010 for which annual deforestation estimates were the priority. Deforestation under the applied forest definition, focused on reporting all forest change greater than 1 hectare in size. Medium resolution sources like Landsat continued to be a practical option, however the risk of incomplete coverage meant alternative satellites such as DMC were considered. DMC was discontinued due to coverage and quality issues. Between 2011 and 2014 RapidEye progressively became the sensor of choice, out of recognition that smaller scale change events, such as new infrastructure and incremental change in mining footprints (greater than 1 hectare in size) prevailed over larger scale ones. Analysis showed that while Landsat was efficient for deforestation report it was not appropriate for forest degradation (at 0.5-1 hectare scale) reporting.

As Guyana embarked on the second phase of its MRV System (2015 to 2019), lower cost satellite options were explored in common with many other countries. Certainly, recent trends point to ever increasing availability of satellites designed to monitor land cover at greater spatial and temporal resolution, leading to greater visibility and monitoring of tropical deforestation (Reiche et al., 2018).

For deforestation mapping a combination of ESA Sentinel 2 and Landsat imagery provides a sound alternative to RapidEye, with close enough resolution and sufficient temporal coverage to generate an annual snapshot of forest change. This is the intended approach for the MRVs for 2019-2020. Sentinel's five-day revisit rate will be leveraged to develop a more real time, continuous monitoring system hosted within the MRVs.

A measure of the MRVs robustness, and consistency can be attained by comparing results of national estimates against those calculated from an independent sample-based assessment. Accuracy assessment reports on the accuracy of the forest change area and attaches confidence limits (i.e. +/$\mathrm{x}$ ha). Guyana is fortunate in that the comparison has been a feature of each reporting period since 2010. The results show a close correspondence across all periods when compared to the area of deforestation generated from the wall to wall national map (Figure 5).

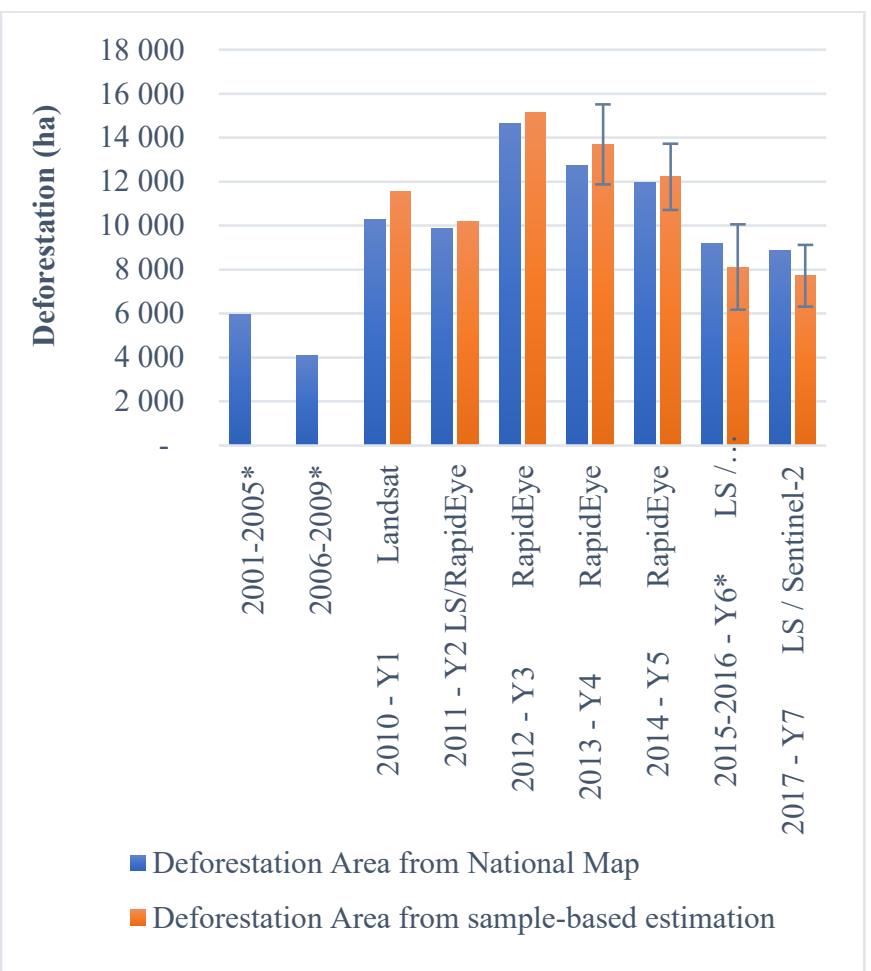

Figure 5. Area comparison between accuracy assessment and the national map

For example, in 2012 the two estimates were within 500 ha using RapidEye, the results of progressive assessments show that the differences also fall within the confidence limits of the sample-based estimate. Essentially this supports the notion that the transition from RapidEye to Sentinel 2 has had little impact on the ability of the MRVs to accurately capture deforestation.

\subsection{Enhancing Resource Management}

Following the commencement of the MRV System in 2009, the outputs generated have significantly enhanced the timeliness, quality and effectiveness of decision-making process as applied to Guyana's natural resources sector. The following summary (Table 5) captures the main decisionmaking and policy impacts derived from the system.

\begin{tabular}{|c|c|c|}
\hline $\begin{array}{c}\text { Data Product } \\
\text { Generated }\end{array}$ & $\begin{array}{c}\text { Natural Resources } \\
\text { Application }\end{array}$ & Impact \\
\hline $\begin{array}{l}\text { Spatial } \\
\text { Mapping of } \\
\text { Protected } \\
\text { Areas }\end{array}$ & $\begin{array}{l}\text { Informing the } \\
\text { Management and } \\
\text { Monitoring Plan for } \\
\text { Protected Areas in } \\
\text { Guyana. Support decision } \\
\text { making on the allocation } \\
\text { of potential new Protected } \\
\text { Areas. }\end{array}$ & $\begin{array}{l}\text { Ensure zero- } \\
\text { deforestation } \\
\text { in Protected } \\
\text { Areas and } \\
\text { maintenance } \\
\text { of Intact } \\
\text { Forest } \\
\text { Landscapes. }\end{array}$ \\
\hline
\end{tabular}




\begin{tabular}{|c|c|c|}
\hline $\begin{array}{l}\text { Informing } \\
\text { Academic } \\
\text { Studies and } \\
\text { Research of } \\
\text { long-term } \\
\text { impacts on } \\
\text { forest } \\
\text { structure }\end{array}$ & $\begin{array}{l}\text { Using a time series of } \\
\text { spatial data from various } \\
\text { sources integrated under } \\
\text { the MRV System and } \\
\text { inform trend analysis of } \\
\text { forest utilization impacts } \\
\text { on long term } \\
\text { sustainability of forest } \\
\text { resources in Guyana. }\end{array}$ & $\begin{array}{l}\text { Sustainable } \\
\text { management } \\
\text { of forest } \\
\text { resources } \\
\text { informed by } \\
\text { scientific } \\
\text { research and } \\
\text { spatial } \\
\text { products, } \\
\text { conducted } \\
\text { locally in } \\
\text { Guyana. }\end{array}$ \\
\hline $\begin{array}{l}\text { Informing a } \\
\text { compliance } \\
\text { monitoring } \\
\text { programme } \\
\text { for the } \\
\text { extractives } \\
\text { sector. }\end{array}$ & $\begin{array}{l}\text { A compliance programme } \\
\text { for proactive monitoring, } \\
\text { leading to improved } \\
\text { allocated for extractive } \\
\text { purposes so to limit forest } \\
\text { impacts. }\end{array}$ & $\begin{array}{l}\text { Maintained } \\
\text { low rate of } \\
\text { deforestation } \\
\text { over the last } 5 \\
\text { years in } \\
\text { Guyana. }\end{array}$ \\
\hline $\begin{array}{l}\text { Informing } \\
\text { national } \\
\text { policy and } \\
\text { reporting on } \\
\text { forest at the } \\
\text { level of } \\
\text { SDGs, } \\
\text { International } \\
\text { Commitments } \\
\text { (Paris } \\
\text { Agreement), } \\
\text { and Bilateral } \\
\text { Agreements. }\end{array}$ & $\begin{array}{l}\text { Guyana's reporting on } \\
\text { progress on its national } \\
\text { Green State Development } \\
\text { Strategy, Paris Agreement } \\
\text { Commitments, areas } \\
\text { under the Rio } \\
\text { Conventions, and SDG } \\
\text { Goal } 13 \text { and } 15 \text { have been } \\
\text { strengthened as a result of } \\
\text { an integrated system of } \\
\text { monitoring forest using a } \\
\text { range of satellite data } \\
\text { streams. }\end{array}$ & $\begin{array}{l}\text { A data } \\
\text { agnostic } \\
\text { system built } \\
\text { by Guyana } \\
\text { with strong } \\
\text { local } \\
\text { capacities to } \\
\text { operate, that } \\
\text { serves } \\
\text { national and } \\
\text { international } \\
\text { monitoring } \\
\text { requirements, } \\
\text { and which } \\
\text { inform } \\
\text { decision } \\
\text { making and } \\
\text { policy setting } \\
\text { for the natural } \\
\text { resources } \\
\text { sector in } \\
\text { Guyana. }\end{array}$ \\
\hline
\end{tabular}

Table 5. Summary of natural resources applications and impacts

\section{CONCLUSION}

From inception the MRVs was designed to include data from multiple sources which can be combined in a consistent manner. The stepwise approach allowing time to bridge gaps in capacity allowing the integration of image processing and time series analysis routines. Today, the potential of the data generated through annual mapping of forest change extends well beyond the intended MRV function to include a range of functions relating to policies, decision-making, integration of compliance functions, and more effective management within the natural resources sector.

Guyana requires spatially explicit forest-based change assessment, as well as precise estimates of the annual area of change in forest cover and degradation. From Guyana's MRVs reporting, it is concluded that there are significant efficiencies in terms of processing time and cost that are achieved through the interoperability of data sets within the national system. It is still the reality that very highresolution data ( $3 \mathrm{~m}$ to $5 \mathrm{~m})$ is often difficult to obtain at an affordable cost from optical satellites. Yet, as countries like Guyana that have a more predominant change matrix of smaller scale change, monitoring less than 1-hectare pockets across the country is necessary to allow for comprehensive, accurate reporting and decision making on forests. There is therefore the clear need to find the balance between what is available and suited to the purpose for Guyana and what is cost effective and accessible. Guyana has adapted its methods over the last 8 years, whilst maintaining uniform standards on definitions, drivers and operating procedures. Over the years, specific methods required refining, to support a flexible, user friendly system. Guyana has been able to adapt these features of the MRV System whilst maintaining the fundamentals of this system.

Recent and evolving developments in the remote sensing environment has opened up many possibilities over the last 4 years, including with a broader range of high resolution optical satellites, higher revisit rates, and online platforms that support a faster and more efficient use of that data, all possible now at country level.

To embrace this dynamic, the MRVS has been built to be data agnostic and this has provided a versatile platform that grows, develops and allows improvements as these became necessary for Guyana. Currently, the MRVs which has been created from the interoperability of various satellite data streams has significantly strengthened decision-making processes. Decisions are more informed, responsive, and well-planned leading to better management of extractive activities, protected areas, and planning for development within forests.

Guyana has shown how the evolving needs of its system has been enabled from the interoperability of various data sets and how these have been integrated to provide the decision support and policy platform for forest management in Guyana.

\section{ACKNOWLEDGEMENTS}

The Guyana Forestry Commission would like to thank the Government of the Kingdom of Norway for its support of Guyana's work on the MRVs development from 2010 to present. The GFC also recognises the role of its close partners Indufor Asia Pacific and Winrock International in the development of the MRV System.

\section{REFERENCES}

Bovolo, C., Donoghue, D., 2017. Has regional forest loss been underestimated? Environmental Research Letters, 12:111003.

Food and Agriculture Organization (FAO), 2011. In: Assessing forest degradation. Towards the development of globally applicable guidelines. UN FAO, Forest Resources Assessment Working 177. http://www.fao.org/docrep/015/i2479e/i2479e00.pdf

Galiatsatos N., Donoghue D.N.M., Watt P., Bholanath P., Pickering J., Hansen M.C., Mahmood, A.R.J., Submitted 
Sensors. An assessment of global forest change datasets for national forest monitoring.

GFOI, 2016. Integration of remote-sensing and groundbased observations for estimation of emissions and removals of greenhouse gases in forests: Methods and Guidance from the Global Forest Observations Initiative, Edition 2.0, Food and Agriculture Organization, Rome.

GOFC-GOLD, 2008. Reducing greenhouse gas emissions from deforestation and degradation in developing countries: a sourcebook of methods and procedures for monitoring and reporting. GOFC-GOLD Report version COP13-2. Global Observations of Forest Cover and Land Dynamics Project Office, Natural Resources Canada, Alberta, Canada. http://www.gofcgold.wur.nl/redd/index.php.

GOFC-GOLD, 2016. A sourcebook of methods and procedures for monitoring and reporting anthropogenic greenhouse gas emissions and removals associated with deforestation, gains and losses of carbon stocks in forests remaining forests, and forestation. GOFC-GOLD Report version COP22-1, (GOFC-GOLD Land Cover Project Office, Wageningen University, The Netherlands).

Goward, S.N., Williams, D.L., Arvidson, T., Rocchio, L.E., Irons, J.R., Russell, C.A., Johnston, S.S., 2017. Landsat's Enduring Legacy: Pioneering Global Land Observations from Space. American Society for Photogrammetry and Remote Sensing, Bethesda, Maryland.

Herold, M., DeFries, R., Achard, F., Skole, D., Townshend, J., 2006. Report of the workshop on monitoring tropical deforestation for compensated reductions GOFC-GOLD Symposium on Forest and Land Cover Observations, Jena, Germany, 21-22 March 2006

Herold M, Román-Cuesta R.M., Mollicone D., Hirata Y., van Laake P., Asner G.P., Souza C., Skutsch M., Avitabile V., MacDicken K., 2011. Options for monitoring and estimating historical carbon emissions from forest degradation in the context of REDD+. Carbon Balance Manag.6:13.

Khorram S., 1999. Accuracy Assessment of Remote Sensing-Derived Change Detection. Ed. S Khorram Bethesda, Maryland: American Society for Photogrammetry and Remote Sensing.

Lehmann E.A., Caccetta P., Lowell K., Mitchell A., Zhou Zs., Held A., Milne T., and Tapley I., 2015. SAR and optical remote sensing: Assessment of complementarity and interoperability in the context of a large-scale operational forest monitoring system. Remote Sensing of Environment. Volume 156, Pages 335-348.

Penman J., Gytarski M., Hiraishi T., Krug T., Kruger D., Pipatti R., Buendia L., Miwa K., et al., 2003. Good Practice Guidance for Land Use, Land-Use Change and Forestry. Intergovernmental Panel on Climate Change,
National Greenhouse Gas Inventories Programme (IPCCNGGIP).

Pickering, J., Stehman, S.V., Tyukavina, A., Potapov, P., Watt, P., Jantz, S.M., Bholanath, P., Hansen, M.C., 2019. Quantifying the trade-off between cost and precision in estimating area of forest loss and degradation using probability sampling in Guyana. Remote Sens. Environ. 221, $122-135$.

Powell, R.L., Matzke, N., de Souza Jr., C., Clarke, M., Numata, I., Hess, L.L., Roberts, D.A., 2004. Sources of error in accuracy assessment of thematic land-cover maps in the Brazilian Amazon, Remote Sens. Environ, 90:221-234.

Reiche J., Hamunyela E., Verbesselt J., Hoekman D., Herold M., 2018. Improving near-real time deforestation monitoring in tropical dry forests by combining dense Sentinel-1 time series with Landsat and Alos-2 PALSAR-2. Remote Sensing of Environment. Volume 204, January 2018, Pages 147-161.

Schingler R.H. Jr., 2015. Perspectives on Public - Private Partnerships in U.S. Earth Observing Programs. Joint Hearing of the Subcommittees for Space and Environment of the House Science Committee (2015)10 p. $\mathrm{http} / / /$ docs.house.gov/meetings/SY/SY16/20151117/10418 1/HHRG-114-SY16-Wstate-SchinglerR-20151117.pdf.

UNFCCC, 2001. The Marrakesh Accords \& The Marrakesh Declaration, advance text, http://www.unfeccc.int/cop7/documents/accords_draft.pdf .

UNFCCC, 2015. Secretariat Report of the Conference of the Parties on its twenty-first session, held in Paris from 30 November to 11 December 2015. Addendum. Part two: Action taken by the Conference of the Parties at its twentyfirst session. In Proceedings of the Report of the Conference of the Parties on its twenty-first session, held in Paris from 30 November to 13 December 2015. Part one: Proceedings.; Paris, 2016; p. 36.

Wulder, M.A., White, J.C., Goward, S.N., Masek, J.G., Irons, J.R., Herold, M., Cohen, W.B., Loveland, T.R., Woodcock, C.E., 2008. Landsat continuity: issues and opportunities for land cover monitoring. Remote Sens. Environ. 112 (3), 955-969.

Wulder M. A., Loveland T.R., Roy D. P. Crawford C.J., Masek J G., Woodcock C. E., Allen R. G., Anderson M. C., Belward A. S., Cohen W. B., Dwyer J., Arb A., Gao F., Griffiths P., Helder D., Hermosilla T., Hipple F. D., Hostert P., Hughes M. J., Huntington J., Johnson D. M., Kennedy R., Kilic A., Li Z., Lymburner L., McCorckel J., Pahlevan N., Scambos T. A., Schaaf C., Schott J. R., Sheng Y., Storey J., Vermote E., Vogelmann J., White J. C., Wynne R. H., Zhu Z., 2019. Current status of Landsat program, science, and application. Remote Sensing of Environment. 225; 127-147. 